\title{
UNDERSTANDING PREFERENCES FOR INCOME REDISTRIBUTION
}

\author{
LOUISE C. KEELY AND CHIH MING TAN
}

\begin{abstract}
Recent research suggests that income redistribution preferences vary across identity groups. We employ a new pattern recognition technology to uncover what these groups are. Using data from the General Social Survey, we present a new stylized fact that preferences for governmental provision of income redistribution vary systematically with race, gender, and class background. We explore the extent to which existing theories of income redistribution can explain our results, but conclude that current approaches do not fully explain the findings.
\end{abstract}

\section{INTRODUCTION}

What determines an individual's preferred level of income redistribution? We present new evidence from the General Social Survey (GSS) that views on whether there should be governmental administration of income redistribution are found to differ along racial, gender, and class lines in the United States. That is, identity groups are found to be salient in describing individual views regarding government's role in the reduction of income inequality.

There is a widely-held view that individuals who are similar tend to have homogenous views on income redistribution. What do we mean when we say that two individuals are similar? The existing empirical literature emphasizes race and gender as important factors in predicting preference for income redistribution ${ }^{1}$. However, to our knowledge, all previous investigations of heterogeneity

Date: May 2004.

Keely: University of Wisconsin, lkeely@ssc.wisc.edu. Tan: Tufts University, chihmingtan@wisc.edu. We are grateful for funding under the Robock Award in Empirical Economics from the University of Wisconsin. Wei-Yin Loh provided invaluable advice on the implementation of the tree regression methods used in this paper. Keely thanks WARF and the Brookings Institution for generous research support, and Brookings for their hospitality. Tan thanks the generous support provided by the Program of Fellowships for Junior Scholars, MacArthur Research Network on Social Interactions and Economic Inequality. We greatly appreciate the excellence and diligence of our research assistant, Zhiguo Xiao. We thank Buz Brock, Steven Durlauf, Carol Graham and Larry Samuelson for comments.

${ }^{1}$ Alesina, Glaeser and Sacerdote [4] and Luttmer [19] examine the role of race, while Edlund and Pande [12] examine the role of gender. Fong [14] and Alesina and La Ferrara [3] include race and gender in their empirical studies, but that do not focus on these variables. 
in redistribution preferences have been carried out using pre-specified identity groups. Doing so potentially leads to misspecification of factors that characterize heterogeneity and results in incorrect inference ${ }^{2}$.

We take a more general approach. We consider a wider range of identity markers, including race and gender, and let the data decide which dimensions are important. To do this, we employ a pattern recognition technology, tree regression analysis, in order to better uncover the role of identity: which aspects of identity are apposite for describing patterns of income redistribution preferences? Also, as the reader shall see, the tree regression method we use has important advantages over regression methods used in related empirical studies.

Theoretical treatments of how income redistribution preferences are determined imply varying roles for identity. These theories fall into two classes. In the first, individual views on redistribution are preference-based. That is, identity matters because people care, in an exogenous fashion, about the actions or outcomes of others in the same or different identity groups. In this view, the relevance of identity to economic decision-making is modeled via modifications to the preference structure.

In the second, identity provides information about an individual's economic circumstances in an environment with uncertainty. The outcomes of others in an agent's identity group may be used to make predictions about her unknown quantity of interest. In information-based theories, identity matters in one of two ways. The actions and outcomes of others can be informational inputs into each individual's decision-making, and identity provides a guide to what information is most salient for this process. Alternatively, identity groupings can correspond to a set of initial conditions that have persistent implications for redistribution preferences. In contrast to preference-based approaches, the preference structures of agents per se are taken to be mutually independent.

These theories imply restrictions on identity's role in determining heterogeneity across a set of subjective and objective outcomes, describing mobility beliefs and socioeconomic status, that are related to income redistribution preferences. We evaluate these restrictions using appropriate questions in the GSS dataset. Our exploration of these empirical restrictions leads us to conclude that existing theories are inadequate in explaining redistribution preferences.

In Section 2, we discuss existing theories of income redistribution preference determination and their empirical implications. In Section 3, the empirical methodology, tree regression analysis, is described and the reasons for its use are explained. In Section 4, we briefly describe the data

\footnotetext{
${ }^{2}$ Manski [20] examines the consequences for estimation of allowing returns to education to vary across identity groups. When identity groups are fixed beforehand by the econometrician, Manski shows that there are serious estimation consequences for defining those groups differently than do individuals. See also Brock and Durlauf [9] for an in-depth discussion of heterogeneity concerns.
} 
and estimation details. In Section 5, we present and interpret our results in the context of the theoretical literature. Section 6 concludes.

\section{TheORIES ON INCOME REDISTRIBUtion PREFERENCES}

2.1. Preference-based theories. The defining feature of preference-based theories is their reliance on an exogenously-specified interdependence of preferences that potentially corresponds to identity groups.

Akerlof and Kranton [1] provide a seminal contribution to the literature on identity by specifying a channel through which identity affects economic decision-making. In their model, an individual's utility depends upon others' actions as well as one's own. Crucially, utility also is dependent on a vector of parameters that describes an individual's identity and his conformity to a set of identity-specific norms. Their paper provides a general specification allowing for interdependence of preferences across prespecified identity groups.

An important example of this type of model is that of Alesina, Baqir and Easterly [2]. They interpret their model as one in which an individual's utility from a public good depends on the extent of its use by members of other ethnic groups. Ethnic diversity in this case is specified as variation in the preference for a public good ${ }^{3}$. Relatedly, Alesina, Glaeser and Sacerdote [4] posit that individual utility is dependent on the utilities of members of other ethnic groups. They conclude that this awareness of ethnic heterogeneity, or "racism", could be responsible for the divergence in views on redistribution across groups.

Because these models do not elicit, but rather assume, which identity groups matter, we know of no direct way of testing whether interdependent preferences truly drive empirical observations. These studies tend to focus on ethnicity as the important identity marker. It is of interest to ascertain whether there are other prominent dimensions of identity.

2.2. Information-based theories. We consider two classes of information-based theories.

In one set of theories, identity serves as a means of categorizing individuals, where identity corresponds to a set of initial conditions. This notion is akin to what Manski [21] terms the correlated effects hypothesis.

Benabou [6] surveys the literature on inequality and its immediate implications for, among other things, redistribution preferences. The basic idea is to link income heterogeneity with variation

\footnotetext{
${ }^{3}$ It is worth noting that models of income redistribution determination also typically employ a lump sum tax with equal transfer across the population. While this is not a general specification of income redistribution, it allows the use of a median voter theorem to arrive at a voting equilibrium. Such a scheme effectively results in a reduction of income inequality.
} 
in private tolerance for inequality, and in turn with differences in the preference for income redistribution. An interesting extension of this mechanism is proposed by Benabou and Ok [7]. They formalize a "prospect of upward mobility" (POUM) hypothesis in order to understand why individuals with less than the population mean income may vote against income redistribution. They show that with a single, commonly-known, concave function that links current to future individual income, a group of voters with incomes less than the mean but above some threshold will vote against redistribution. They do so because the concavity of the mobility process leads them to expect a higher than average income in the next period.

This model predicts that patterns of heterogeneity in income, tolerance for inequality, and preference for income redistribution should be related, with a one-to-one correspondence between the latter two. In this framework there is no distinction between one's values concerning income inequality and one's voting decision on a specific redistribution policy. We would expect to find that any categorization according to identity of redistribution preferences matches those for tolerance of inequality ${ }^{4}$.

In a second set of theories, identity is viewed as a source of information about one's outcome in an environment with uncertainty. In what Manski [21] terms endogenous interactions, agents extract information from observing the actions and outcomes of others. Loury [18] argues that people are 'socially located' - they are part of social and cultural networks that exert strong influence on behavior. Behavior may be ex-post rational in that it is self-fulfilling and persistent. As a result, initial differences across groups can have long run effects on outcomes such as income or preferences for income redistribution.

Piketty [22] presents a model in which there is a single mobility process that is unknown to agents. Also, agents exhibit a common social welfare function representing a shared tolerance for income differences. Agents learn from past mobility experience to form beliefs about the true mobility process. In this framework, mobility beliefs are directly inform preferences for income redistribution. Further, mobility beliefs are parameterized to correspond to views on the relative importance of luck and hard work in determining one's future income.

According to this model, long-run differences in preference for redistribution and mobility beliefs are a result of two forces. Initial differences in the priors over the true mobility process are one factor. A second is that individual learning process about the mobility process use incomplete information that varies across individuals. Specifically, individuals use information only from their own past experience and the population's average experience, and individuals do not experiment in order to learn.

\footnotetext{
${ }^{4}$ Further, in Benabou and Ok, the complexity of these categorizations is no larger than the complexity of categorization with regard to income with a binary choice over redistribution policies.
} 
Piketty provides a framework in which a single true mobility process and a common abstract tolerance for inequality can co-exists with heterogenous mobility beliefs that drive variation in preferences for income redistribution. It is straightforward to introduce a role for identity, akin to that suggested by Loury and Manski, into this framework by having individuals extend their learning to a reference group that is based on identity. In this setting, heterogeneity in mobility beliefs and income redistribution preferences will correspond to these reference groups ${ }^{5}$.

Both types of information-based models suggest that we should observe identity groupings for current income that are at least as complex as that for redistribution preferences. For instance, in Piketty's framework, mobility beliefs within reference groups converge over time, although they may differ across groups. Income heterogeneity will not converge because it is determined in part by a stochastic process that is exogenous to beliefs.

2.3. An illustrative framework. Formally, let $y \in Y$ denote an outcome of interest and let $x \in X$ be a vector of identity markers. We view the population of individuals as being classified by their identity markers into an unknown number $b$ of subpopulations indexed by $j$. This classification divides the space of $X$ into $b$ partitions, $\Lambda=\left\{A_{1}, \ldots, A_{b}\right\}$. The partitions $A_{j}$ are mutually exclusive and their union is $X$ :

$$
A_{j} \cap A_{k}=\emptyset \forall j \neq k
$$

and

$$
\bigcup_{j=1}^{b} A_{j}=X
$$

For example, suppose $y$ measures redistribution preferences and $x=($ Race, Sex $)$ where Race takes on values $\{B, W\}$ and Sex takes on values $\{M, F\}$. Then, a possible set of identity partitions, $\Lambda=\left\{A_{1}, A_{2}, A_{3}\right\}$, is $\{(B F, B M),(W M),(W F)\}$.

All members of a given subpopulation are assumed to draw $y$ from the same distribution. That is, the distribution of $y$ across the whole population, $g_{y}$, is a mixture distribution with $b$ components. Each component is a parametric distribution indexed by $j, f_{y}\left(\theta_{j}\right)$ where $\theta_{j}$ are the distribution parameters for $j=1, \ldots, b$. Each subpopulation weight $\pi\left(A_{j}\right)$ for $j=1, \ldots, b$ is the proportion of individuals whose identity markers fall into the partition $A_{j}$ :

$$
g_{y}=\sum_{j=1}^{b} \pi\left(A_{j}\right) f_{y}\left(\theta_{j}\right)
$$

\footnotetext{
${ }^{5}$ For long run heterogeneity in mobility beliefs, we require that these reference groups vary in their priors regarding a true mobility process and that income heterogeneity across reference groups be such that the reference groups' income distributions do not span the entire support of income.
} 
and

$$
\sum_{j=1}^{b} \pi\left(A_{j}\right)=1 .
$$

Suppose there are two outcomes of interest, $y_{1}$ and $y_{2}$, where $y_{2}$ measures the preference for redistribution of income. A theory of redistribution preference may imply a mapping $f$ of the partition $\Lambda_{1}$ corresponding to $y_{1}$ into the partition $\Lambda_{2}$ corresponding to $y_{2}$. Under Piketty's theory, $f$ implies that $\Lambda_{1}=\Lambda_{2}$ where $y_{1}$ represents mobility beliefs. Under the framework of Benabou and Ok, $f$ implies $\Lambda_{1}=\Lambda_{2}$ where $y_{1}$ represents private tolerance for inequality. Specifically, in the former, heterogeneity in income redistribution preferences co-exists with analogous heterogeneity in mobility beliefs and homogenous tolerance of inequality. In the latter, heterogeneity in income redistribution preferences is present alongside analogous heterogeneity in tolerance of inequality and homogenous mobility beliefs. In both settings, a partition $\Lambda_{1}$ corresponding to current income as $y_{1}$ should have at least as many elements of $\Lambda_{2}$. The elements of $\Lambda_{1}$ should represent subsets of the elements of $\Lambda_{2}$.

We proceed to investigate these implications.

\section{EMPirical METHODOLOGY}

3.1. Tree regression analysis. The empirical strategy is to uncover patterns of heterogeneity for a set of outcome, i.e. dependent, variables. To do so, we use a set of identity markers to classify the responses of these outcome variables into groups. The number and composition of these groups are endogenously determined, as will be explained. Each identity marker is treated as an independent variable. Identity questions were chosen that are not choice variables of the respondent. This strategy avoids traditional endogeneity concerns and also avoids potential bias due to measurement error when using a subjective outcome as an independent variable (see Hamermesh [15]).

It is of interest to understand what the relationship is between subjective or endogenous outcomes, such as between redistribution preferences and mobility beliefs. However, it is inappropriate to regress one subjective (or endogenous) outcome on another, as Hamermesh makes clear. We therefore pursue another strategy for understanding this relationship. That is, we combine a different empirical approach laid out below with the implications of existing theories laid out above.

The econometric technique we will use to examine the relationship between identity markers and preference for redistribution is tree regression analysis. Tree regressions are a pattern recognition tool; they deliver insight into the classification of a population with reference to a dependent variable. The tree regression partitions observations according to an algorithm that attempts to maximize predictive performance. Tree regressions are particularly useful because they endogenously generate the groupings. The groupings are not pre-specified. 
Concretely, tree regression techniques deliver estimates for $\left(b,\left\{A_{j}\right\}_{j=1}^{b}, \Theta=\left\{\theta_{j}\right\}_{j=1}^{b}\right)$ where, as noted above, $b$ is the number of groups, $\left\{A_{j}\right\}_{j=1}^{b}$ is the set of identity partitions, and $\Theta$ is the set of distribution parameters corresponding to each identity group. As a by-product, automatic variable selection is achieved in the sense that only the relevant combinations of identity markers are selected. Partitions which are not salient are not considered in determining $\left\{A_{j}\right\}_{j=1}^{b}$. That is, all other proposed, extraneous identity markers are dropped.

\subsection{Generalized Unbiased Interaction Detection and Estimation (GUIDE) tree regres-}

sions. The specific tree regression algorithm we use in our empirical exploration is GUIDE tree regressions. Loh [17] is the key reference. GUIDE is an extension of the well-established Classification and Regression Tree (CART) methodology by Breiman, Friedman, Olsen, and Stone [8]. GUIDE's innovation is to minimize the variable selection problem found in CART (see Doyle [10]) using a simple test for linear fit.

GUIDE constructs an overly large tree by iteratively dividing the population into smaller and increasingly homogeneous subsets. At each stage, the given population is divided into exactly two subgroups. This division is done by locating an identity marker and split value for that marker that minimize the classical linear regression sum of squared errors across both groups. The overly large tree is then pruned back using a criterion that maximizes fit and penalizes for complexity similar to an information criterion. The result of this procedure is that individuals are classified into groups, the members of which are homogenous in the statistical sense. In our context, the expected preference for redistribution is the same for all individuals within a group. The reader is referred to the Technical appendix for details on the GUIDE procedure.

\section{Data And EMPirical analysis}

We use data from the General Social Survey (GSS) in our empirical study of the correspondence in the United States between identity, redistribution preferences, and related variables. A variety of topics are covered in the survey, such as political activism, child-rearing, religious beliefs, and women's rights. Demographic variables such as the respondent's age, sex, income bracket, socioeconomic status, and education level are also collected. The samples are intended to be nationally representative of adults over 18 , with weighting of certain groups. ${ }^{6}$

4.1. Identity markers. Several identity variables in the GSS are used in each tree regression to constitute the vector $x$. A summary of these variables is provided in Table 1 .

\footnotetext{
${ }^{6}$ The oversample of blacks in the 1982 and 1987 waves of the GSS were not included.
} 
The identity variables are the respondent's age in years (AGE), his gender (SEX), his selfreported race $^{7}$ (RACE); the region of the US in which he was living at 16 (REGION), whether the respondent was born in the US (BORN), whether the respondent's parents were born in the US (PARBORN), the respondent's mother's highest educational degree as a proxy of socioeconomic background (MADEG), what religion in which the respondent was raised (RELIG16), and the respondent's description of his religious upbringing as fundamentalist, moderate or liberal (FUND16). A trend variable (YEAR) is also included. Details of these questions, as relevant, are provided in the Data appendix. Given the data constraints, we have chosen the most appropriate proxies available of exogenous identifiable characteristics.

4.2. Dependent variables. In our selection of dependent variables, we pay careful attention to choosing the closest proxy to each object of interest. We also try different proxies and multiple years of data in order to investigate the robustness of our results. A summary of the variables used is provided in Table 2 .

The first type of scalar dependent variable $y$ measures redistribution preferences. Two survey questions are considered ${ }^{8}$. The first asks about views on governmental redistribution to reduce income differences (EQWLTH). The redistribution question is asked in each wave of the GSS between 1978 and 2000. The second asks about whether the level of welfare spending is too high or too low (NATFARE). For consistent comparison, the sample considered is also each survey wave between 1978 and 2000. The reader is referred to the Data appendix for further details on each dependent variable.

Both of these questions include explicit reference to a governmental role in redistribution. Differences in responses can be understood in one of three ways. First, variation could be due to individual differences in tolerance for inequality. Second, variation could be attributed to differences in individuals' general confidence in government. Third, there may just be individual variation in the particular question of whether income redistribution should be publicly provided. In order to investigate these alternatives, we will compare our results for EQWLTH and NATFARE with two questions that ask the respondent's view on the fairness of income differences (INCGAP and WHYPOOR4), and with two questions that ask about the respondent's confidence in federal governmental institutions (CONFED and CONLEGIS).

We will exploit the theoretical implications described above in order to gain insight into our tree regression results for EQWLTH and NATFARE. Recall that the Benabou and Ok framework

\footnotetext{
${ }^{7}$ This question asks the respondent to identify himself as white, black, or other. While we would have preferred a question with more ethnic detail, this was the best question that the GSS offered over many waves.

${ }^{8}$ These questions are used in related empirical studies. Alesina and La Ferrara [3] use both EQWLTH and NATFARE. Luttmer [19] employs NATFARE in his work.
} 
predicts matching identity groups for redistribution preferences and views on inequality. Therefore, we would expect the trees for EQWLTH and NATFARE to be similar to those of INCGAP and WHYPOOR4.

Next, as we noted above, Piketty's theory can imply corresponding identity groupings for the redistribution preference dependent variables and those that describe mobility beliefs, particularly views on hard work versus luck. One question we employ directly asks about their relative importance (GETAHEAD), two questions ask only about the role of hard work in getting ahead (OPHRDWK and LFEHRDWK).

One might question the generality of the questions on hard work as proxies for mobility beliefs. We offer alternative proxies for mobility beliefs, and consider two questions that provide an evaluation of the respondent's actual mobility. This approach is based on a presumption that actual mobility informs mobility beliefs. One variable we construct is the absolute value of the difference between the respondent's education level and that of his or her father (PADEG_ABS_DIFF). The second is a variable that measures the respondent's perceived standard of living now relative to his parents at the same age ${ }^{9}$ (PARSOL). A third question provides an evaluation of expected dynastic mobility, and asks the respondent to compare his standard of living to that expected for his children at a similar age (KIDSSOL).

This implication is examined by comparing tree regressions of alternative measures of current income: real family income (REALINC), respondent's income (REALRINC), and the respondent's education level (DEGREE) with those of redistribution preferences.

\section{Results}

The regression trees were constructed using pooled data for all years between 1978 and 2000 in which the relevant dependent variable was asked. As a check on the robustness of the results, all of the tree regressions described below were also constructed using data from several individual years. The results discussed in this section are summarized in Tables 3-8. For an example of a graphical representation of a tree regression, see Figures 1-7 that depict the trees too large to summarize in the Tables.

\footnotetext{
${ }^{9}$ We do not include results for PADEG_DIFF which is the pure difference between the respondent's degree level and his father's. The results are similar to those for PADEG_ABS_DIFF. However, Fields and Ok [13] provides an axiomatic justification for PADEG_ABS_DIFF that does not hold for PADEG_DIFF. Also, PADEG_DIFF will inevitably result in an uninterpretable distribution of responses since the education variables are by construction censored above and below.

We also do not employ a question that asks about the respondent's job status relative to his or her father's. This question seems difficult to interpret in that perceptions of job status potentially vary over time and across individuals.
} 
5.1. Regarding redistribution preferences. The tree regressions using the redistribution preference variables (EQWLTH and NATFARE) as the dependent variable are discussed first.

The regression trees using EQWLTH have the following robust features. The groups are based on sex and race, and correspond to white males, white females, and all others. White males are least in favor of governmental intervention to reduce income differences, followed by white females, and with all others most in favor of a role for government. There is also less robust evidence that, among whites, men and women also differ by their mother's education level. In particular, those whose mothers did not finish high school have a stronger preference for income redistribution than those whose mothers at least finished high school.

The robust groupings for NATFARE overall correspond to whites and other races. Whites tend to think there is too much spending on welfare, whereas others on average think spending is about right. However, there is also some evidence that there is interesting variation over time in these views. Two time periods in the sample that have been viewed as watersheds for American social policy: when Reagan became president in 1981, and when major welfare reform was undertaken in 1996 during Clinton's administration. While non-white views on welfare tend to be roughly constant over these periods, whites tend to have views closer to those of non-whites after the turning points as compared to just before. Our interpretation is that this time variation is due to the specific policy nature of this question on welfare, in contrast to EQWLTH. EQWLTH asks more generally about government's role in redistribution. Nevertheless, the racial distinction is persistent across time for NATFARE.

One question raised above is whether variation in responses to these redistribution preference questions is due to individual variation in the general confidence in government. Using the questions CONFED and CONLEGIS, we find some possible consistency with the heterogeneity uncovered in NATFARE. There are groupings for CONFED that correspond to Republican administration years on the one hand and Democratic administration years on the other. Within the Republican years, there are also prominent racial groups: blacks and whites ${ }^{10}$. These racial groups do not appear in the Democratic years. Confidence in the executive branch is on average higher in the Republican years than in the Democratic years, and higher among whites than among blacks.

There are groupings for CONLEGIS according to the watershed years. However, there is generally no classification by race, or any other identity marker, for CONFED or CONLEGIS when running the tree regressions using individual years of the survey. This finding is in contrast to NATFARE, for which racial classifications are robust.

\footnotetext{
${ }^{10}$ The racial groups here are actually blacks and non-blacks. However, because the non-black, non-white group consists of such a small number of observations and are such a heterogenous group, we focus on white-black differences.
} 
Thus, there may be some relationship between confidence in government and views on welfare spending, but the evidence is suggestive at best. We have to look elsewhere to understand the identity groupings that delineate redistribution preferences.

We next ask whether variation in redistribution preference can be attributed to differences in tolerance for inequality. Though a framework such as that of Benabou and Ok would predict such a relationship, we do not find evidence to suggest this is the case. The robust finding is that there is no systematic heterogeneity in these views. On average, there is moderate agreement that differences in income are too large in the United States ${ }^{11}$. However, lack of effort by the poor is viewed, on average, to be reasonably important in explaining why some people are poor ${ }^{12}$.

Therefore, there appears to be a confluence of factors having to do with both views on inequality and views on government which result in the particular groupings uncovered for redistribution preferences, and that cannot be explained by one or the other factor. Americans share a common concern about inequality and a belief in the ability to escape poverty through hard work. But this consensus does not carry over to redistribution preferences.

5.2. Comparison with mobility beliefs. An implication of Piketty's model and the hypothesis of endogenous interactions is that heterogeneity in mobility beliefs drives heterogeneity in redistribution preferences. Therefore, we examine whether identity classifications for redistribution preferences match those for mobility belief variables. The results suggest that this is not the case.

We find no evidence of systematic heterogeneity in any of the three questions considered that describe views on mobility. The views across questions are remarkably consistent, and display a strong belief in the importance of hard work in improving one's lot in life. Average responses to the question GETAHEAD fall about halfway between 'hard work most important' and 'hard work, luck equally important' in contributing to people getting ahead. Similarly, the average response to OPHRDWRK is between 'essential' and 'very important'; that of LFEHRDWRK is between 'very important' and 'important'. These results are consistent with other research suggesting that Americans believe in the importance of hard work, as opposed to initial conditions or luck, in determining one's socioeconomic outcome (see Keely [16] and references therein).

To allow for the possibility that questions about hard work's importance do not adequately proxy for mobility beliefs, another possibility is considered. Perhaps a respondent's mobility beliefs are influenced by evaluation of his past or future mobility. In that case, identity classifications for past mobility should inform identity groupings for redistribution preferences.

\footnotetext{
${ }^{11}$ The average responses to INCGAP fall between the responses 'agree' and 'neither agree nor disagree' in each survey year.

${ }^{12}$ The average response to WHYPOOR4 is between 'very important' and 'somewhat important'.
} 
When asked to compare one's standard of living to one's parents' at the same age (PARSOL) the only robust classification is by respondent's age. Respondents over the age of 55 have a higher assessment of their standard of living, relative to their parents', than do people under 55. There is an important intergenerational response, one that is not observed when considering responses to redistribution preferences.

We also find using PADEG_ABS_DIFF that, across age groups, the robust feature of identity groupings is that those whose mother had low levels of education exhibit lower actual mobility, up or down, compared to mobility of other respondents ${ }^{13}$. This finding is consistent with the notion of poverty traps (see Durlauf [11]). Each of these groupings constitutes a significant proportion of the sample population. We view this finding as important in that both predicted levels of mobility correspond to sizeable populations. This suggests that poverty traps have real social implications.

Finally, KIDSSOL reveals an instability in evaluation over time of dynastic prospects, as the data groups into years. In the later waves there is also significant heterogeneity according to race, as whites group apart from non-whites. The racial groupings are not robust to running tree regressions on individual sample years. In the regressions using only individual years, no identity marker groups the responses to KIDSSOL.

In contrast to what one would expect from theory, we do not find a concurring set of identity groupings for mobility beliefs and redistribution preferences. Rather, whatever forces drive heterogeneity in mobility beliefs do not appear to be the same as those at work for redistribution preferences.

5.3. Comparison with socioeconomic status. As noted above, we would expect from informationbased theories on the determination of redistribution preferences that heterogeneity of identity groupings for redistribution preferences is less complex than that for variables measuring socioeconomic status.

There do in fact appear to be more complex groupings for respondent's income and education variables than for redistribution preference variables. Moreover, there is some comparability in heterogeneity patterns across the two types of questions. Examining the respondent's real income (REALRINC), classifications according to race, sex and mother's education are broadly consistent with those for EQWLTH and NATFARE. However, further complexity is present in the groupings for REALRINC. There is more complexity still when examining the respondent's real family income

\footnotetext{
${ }^{13}$ Respondents less than or equal to 33 years old and with native born parents group according to whether MADEG is less than or equal to two, or greater than two. Respondents over 33 group according to whether MADEG is equal to zero or greater than zero.
} 
(REALINC) and his education level (DEGREE). There is some weak evidence for informationbased models that posit correlation effects.

\section{Conclusion}

The key message of this paper is that understanding patterns of heterogeneity in outcome variables is crucial. The revealed structure of heterogeneity can yield interesting insights. If it is ignored, misleading conclusions may result. Existing empirical work on income redistribution preferences generally pays too little attention to these concerns.

We provide new stylized facts regarding salient heterogeneity patterns for preferences regarding government provision of income redistribution. We find that general views on redistribution are heterogeneous according to race, sex, and class background, while specific views on welfare are heterogeneous according to race only. We cannot explain these patterns by variation in overall confidence in government, nor differences according to identity groups in an abstract tolerance for inequality. It therefore appears that there is something particular about the role of government with regard to this policy that drives the particular form of heterogeneity observed. This raises a theoretical challenge: how can it be that we have no systematic differences in inequality tolerance or confidence in government, yet still have such differences in government-administered income redistribution?

Existing information-based theoretical models do not appear to completely explain our empirical results. The empirical patterns of systematic heterogeneity for mobility beliefs and abstract inequality tolerance are not consistent with patterns predicted by theory. We conclude that while these models provide important insight into the process of redistribution preference determination, they do not tell the whole story. This is a potentially important area for future research.

Our results also imply that the salient groupings relevant for preference-based theories of redistribution preferences go beyond ethnicity, except perhaps when talking about a specific policy such as welfare. In general, we find these groupings are more complex, reflecting also differences based on gender and class background. Perhaps surprisingly, religious background, both in terms of denomination and ideology, does not play a role in describing systematic heterogeneity in redistribution preference. Religious background and its influence on individual income differences, as well as cross-country growth differences, have been the subject of many studies ${ }^{14}$.

In our view, the results of this paper constitute a puzzle to be resolved in future research.

\footnotetext{
${ }^{14}$ For examples of work on religion and its effect on income, see Sander [23] and Tomes [24]. For an example of work on religion and its effect on growth, see Barro and McCleary [5].
} 


\section{REFERENCES}

[1] G. A. Akerlof and R. E. Kranton. Economics and identity. Quarterly Journal of Economics, 115(3):715-753, 2000 .

[2] A. Alesina, R. Baqir, and W. Easterly. Public goods and ethnic divisions. Quarterly Journal of Economics, 114(4):1243-1284, 1999.

[3] A. Alesina and E. L. Ferrara. Preferences for redistribution in the land of opportunities. Working paper, Harvard University, 2004.

[4] A. Alesina, E. Glaeser, and B. Sacerdote. Why doesn't the United States have a European-style welfare state? Brookings Papers on Economic Activity, 2, 2001.

[5] R. J. Barro and R. McCleary. Religion and economic growth. Working Paper 9682, NBER, 2003.

[6] R. Benabou. Inequality and growth. Working Paper 5658, NBER, 1996.

[7] R. Benabou and E. A. Ok. Social mobility and the demand for redistribution: The POUM hypothesis. The Quarterly Journal of Economics, 2001.

[8] L. Breiman, J. Friedman, R. Olsen, and C.J.Stone. Classification and Regression Trees. Wadsworth, 1984.

[9] W. A. Brock and S. N. Durlauf. Growth empirics and reality. Working Paper 8041, NBER, 2000.

[10] P. Doyle. The use of automatic interaction detector and similar search procedures. Operational Research Quarterly, 24:465-467, 1973.

[11] S. N. Durlauf. A theory of persistent income inequality. Journal of Economic Growth, 1(1):75-93, 1996.

[12] L. Edlund and R. Pande. Why have women become left-wing? the political gender gap and the decline in marriage. Quarterly Journal of Economics, 117(3), 2002.

[13] G. S. Fields and E. A. Ok. The measurement of income mobility: An introduction to the literature. In J. Silber, editor, Handbook on Income Inequality Measurement, pages 557-598. Kluwer Academic Publishers, 1999.

[14] C. Fong. Social preferences, self-interest, and the demand for redistribution. Journal of Public Economics, 82(2), 2001.

[15] D. S. Hamermesh. Subjective outcomes in economics. Southern Economic Journal, July 2004.

[16] L. C. Keely. Perceived return to human capital in fertility. Working paper, University of Wisconsin, March 2004.

[17] W.-Y. Loh. Regression trees with unbiased variable selection and interaction detection. Statistica Sinica, 12:361386,2002 .

[18] G. C. Loury. Discrimination in the post-civil rights era: Beyond market interactions. Journal of Economic Perspectives, 12(2):117-126, 1998.

[19] E. F. Luttmer. Group loyalty and the taste for redistribution. Journal of Political Economy, 109(3):500-528, 2001.

[20] C. F. Manski. Dynamic choice in social settings: Learning from the experiences of others. Journal of Econometrics, 58(1-2):121-136, 2000.

[21] C. F. Manski. Economic analysis of social interactions. Journal of Economic Perspectives, 14(3):115-136, 2000.

[22] T. Piketty. Social mobility and redistributive politics. Quarterly Journal of Economics, 110(3):551-584, 1995.

[23] W. Sander. Catholicism and the economics of fertility. Population Studies, 46(3):477-489, 1992.

[24] N. Tomes. The effects of religion and denomination on earnings and the returns to human capital. The Journal of Human Resources, 19(4):472-488, 1984. 


\section{Technical Appendix}

GUIDE is an extension of the established CART software (see Breiman et al (1984)) that minimizes the variable selection problem found in the latter (see Doyle (1973)) as well as making possible more complicated terminal node model structures. It solves the regressor (splitting variable) selection bias problem using a simple test for linear fit to select a splitting variable. The choice of split points for selected splitting variables is carried out by choosing the value in the support of the splitting variable that minimizes the sum of squared residuals across regressions of each group. The overall size of the tree is determined using cost-complexity pruning with $V$-fold cross-validation; again, similar to the CART procedure. In this appendix, we reproduce and detail the key GUIDE algorithms from the main reference used in this paper. Loh (2002) provides more details about GUIDE as well as a description of other tree generating options within GUIDE.

First, define the following classes of covariate variables:

- $n$-variable : a numerical-valued predictor used to fit the terminal node regression model and to split the nodes in the tree;

- $f$-variable : a numerical-valued predictor used to fit the terminal node regression model but not to split the nodes in the tree;

- $s$-variable : a numerical-valued predictor used to split the nodes in the tree but not to fit the terminal node regression model;

- $c$-variable : a categorical predictor used to split the nodes in the tree but not to fit the terminal node regression model.

The first two algorithms determine the choice of the splitting variable at each node of the tree.

Chi-square tests for linear fit.

- Obtain the residuals from a linear model fitted to the n- and f-variables, leaving out the sand c-variables.

- For each n-variable, divide the data into four groups at the sample quartile; construct a 2 $\times 4$ contingency table with the signs of the residuals (positive versus non-positive) as rows and the groups as columns; count the number of observations in each cell and compute the $\chi^{2}$-statistic and its theoretical p-value from a $\chi_{3}^{2}$ distribution.

- Do the same for each s- and c-variable. For the latter, the categories of the variable form the columns of the table. Columns with zero column totals are omitted.

- To detect interactions between each pair of n-variables $\left(X_{i}, X_{j}\right)$, divide the $\left(X_{i}, X_{j}\right)$-space into four quadrants by splitting the range of each variable into two halves at the sample 
median; construct a $2 \times 4$ contingency table using the residual signs as rows and the quadrants as columns; compute the $\chi^{2}$-statistic and p-value. Again, columns with zero column totals are omitted.

- Do the same for each pair of s-variables.

- Also do the same for each pair of c-variables using their value pairs to divide the sample space. For example, if $X_{i}$ and $X_{j}$ take $c_{i}$ and $c_{j}$ unique values, respectively, the $\chi^{2}$-statistic and $\mathrm{p}$-value are computed from a table with 2 rows and number of columns equal to $c_{i} c_{j}$ less the number of zero columns.

- Compute a $\chi^{2}$-statistic and p-value for each pair $\left(X_{i}, X_{j}\right)$ where $X_{i}$ is an n-variable and $X_{j}$ is a c-variable. If $X_{j}$ has c categories, the table has 2 rows and number of columns equal to $2 \mathrm{c}$ less the number of zero columns.

- Similarly, compute a $\chi^{2}$-statistic and p-value for each pair $\left(X_{i}, X_{j}\right)$ where $X_{i}$ is an s-variable and $X_{j}$ is a c-variable.

- Finally, do the same for each pair where $X_{i}$ is an s-variable and $X_{j}$ is a n-variable as in step 4.

Choosing the splitting variable.

- Note that 9 sets of Chi-square tests are computed: 3 sets to detect curvature in the n-, s-, and c-variables, 3 sets to detect interactions between pairs of variables of the same type, and 3 sets to detect interactions between pairs of predictors of different types.

- If the smallest p-value comes from a curvature test, the associated variable is selected to split the node.

- Suppose instead that a pair of variables is selected because their interaction test is the most significant among the curvature and interaction tests.

- If neither is a n-variable, choose the one with the smaller curvature p-value.

- If both are n-variables, temporarily split the node along the sample mean of each variable; choose the variable whose split yields the smaller total SSE.

- If exactly one is an n-variable, choose the other variable.

Once a splitting variable (call it $X_{j}$ ) has been chosen, we need to determine the split value for that variable. This is done in the next algorithm.

Choosing the split value. 
- Consider the two partitions of the sample space $Y \times X$ defined as follows,

$$
\begin{aligned}
& A_{1}^{j}(s)=\left\{\left(y_{i}, X_{i}\right) \in Y \times X \mid x_{j}^{i} \leq s\right\} \\
& A_{2}^{j}(s)=\left\{\left(y_{i}, X_{i}\right) \in Y \times X \mid x_{j}^{i}>s\right\}
\end{aligned}
$$

where $i=1, \ldots, n$ indexes obervations and $x_{j}^{i} \in X_{j}$ for all $i$.

- The task is to determine the value $s$.

- Let $\hat{\beta}_{(j, s)}^{1}$ be the OLS estimator of the regression of $Y$ on $X$ for the subset of observations that conforms to the partition $A_{1}^{j}(s)$, and $\hat{\beta}_{(j, s)}^{2}$ be the OLS estimator of the regression of $Y$ on $X$ for observations conforming to partition $A_{2}^{j}(s)$.

- Find the split value $s$ for splitting variable $X_{j}$ that minimizes the sum of squared residuals (SSR):

$$
\sum_{\left(y_{i}, X_{i}\right) \in A_{1}^{j}(s)}\left(y_{i}-X_{i} \hat{\beta}_{(j, s)}^{1}\right)^{2}+\sum_{\left(y_{i}, X_{i}\right) \in A_{2}^{j}(s)}\left(y_{i}-X_{i} \hat{\beta}_{(j, s)}^{2}\right)^{2}
$$

To grow a tree, therefore, GUIDE starts with the set of all observations and applies the three algorithms above to find a splitting variable and a split value leaving two mutually exclusive subsets of observations the union of which forms the set of all observations. It then continues to apply this same procedure to each of the resultant subsets, and then to the subsets of observations resulting from those, and so forth iteratively until the number of observations in the subset falls below a certain predetermined value. In our exercises, we take this minimum number of observations to be the default value set by GUIDE. After the tree is grown, it has to be "pruned" in order to avoid overfitting the data. This is done using Cost Complexity pruning.

\section{Cost Complexity Pruning}

- First denote the fully-grown tree to be pruned as $T_{0}$. Now, consider a sub-tree $T \subset T_{0}$ with $b$ terminal nodes.

- Define the Cost Complexity criterion for given $\alpha$ (as applied to sub-tree $T$ ) as,

$$
C_{\alpha}(T)=\sum_{m=1}^{b} \sum_{\left(y_{i}, X_{i}\right) \in T N(m)}\left(y_{i}-X_{i} \hat{\beta}_{m}\right)^{2}+\alpha \cdot b
$$

- The idea behind the use of the Cost Complexity criterion is to attempt to minimize SSR but to penalize overfitting through the use of an overly complex tree.

- Denote the tree for which $C_{\alpha}(T)$ is minimized (for given $\alpha$ ) as $T_{\alpha} \subseteq T_{0}$.

- The SSR for $T_{\alpha}$ is obtained by cross-validation.

- Choose the tree for which $\alpha$ minimizes the cross-validated SSR. 
For the GUIDE generated trees reported in this paper, the covariate in the terminal node model consists only of a constant. $V$ was set to the maximum value available.

\section{DATA APPENDIX}

\subsection{Dependent variables.}

\subsubsection{Preference for public redistribution.}

(1) EQWLTH (1978-2000): Some people think that the government in Washington ought to reduce the income differences between the rich and the poor,perhaps by raising the taxes of wealthy families or by giving income assistance to the poor. Others think that the government should not concern itself with reducing this income difference between the rich and the poor. Here is a card with a scale from 1 to $\%$. Think of a score of 1 as meaning that the government ought to reduce the income differences between rich and poor, and a score of 7 meaning that the government should not concern itself with reducing income differences. What score between 1 and 7 comes closest to the way you feel?

(2) NATFARE (1978-2000): We are faced with many problems in this country, none of which can be solved easily or inexpensively. I'm going to name some of these problems, and for each one I'd like you to tell me whether you think we're spending too much money on it, too little money, or about the right amount. Are we spending too much, too little, or about the right amount on welfare? $(1=$ Too little, $2=$ About right, $3=$ Too much $)$

\subsubsection{Tolerance for inequality.}

(1) INCGAP (1987, 1996, 2000): Do you agree or disagree. Differences in income in America are too large. $(1=$ Strongly agree, $2=$ Agree, $3=$ Neither agree nor disagree, $4=$ Somewhat disagree, 5 = Strongly disagree)

(2) WHYPOOR4 $4^{15}$ (1990): Now I will a list of reasons some people give to explain why there are poor people in this country. Please tell me whether you feel each of these is very important, somewhat important, or not important in explaining why there are poor people in this country. Lack of effort by the poor themselves $(1=$ Very important, $2=$ Somewhat important, 3 = Not important)

\footnotetext{
${ }^{15}$ The question is interpreted in this case as giving insight into a person's view of the fairness of inequality. It could also be interpreted as a question about mobility beliefs, i.e. whether it is possible for the poor to increase their income via hard work. Our results are invariant to the interpretation of this question.
} 


\subsubsection{Mobility beliefs.}

(1) GETAHEAD (1980-2000): Some people say that people get ahead by their own hard work; others say that lucky breaks or help from other people are more important. Which do you think is most important? ( 1 = Hard work most important, 2 = Hard work, luck equally important, 3 = Luck most important)

(2) OPHRDWK (1987): Please show for each of these how important you think it is for getting ahead in life . . Hard work - how important is that for getting ahead in life? $(1=$ Essential, 2 = Very important, $3=$ Fairly important, $4=$ Not very important, $5=$ Not important at all)

(3) LFEHRDWK (1993): I'm going to read some statements that give reasons why a person's life turns out well or poorly. As I read each one, tell me whether you think it is very important, important, somewhat important, or not at all important for how somebody's life turns out? Some people use their will power and work harder than others. $(1=$ Very important, 2 = Important, 3 = Somewhat important, $4=$ Not at all important)

\subsubsection{Mobility.}

(1) PADEG_ABS_DIFF (1978-2000): Absolute difference between DEGREE and PADEG. DEGREE is respondent's highest educational degree and PADEG is respondent's father's highest educational degree. See DEGREE below that gives categories for both questions.

(2) PARSOL (1994-2000): Compared to your parents when they were the age you are now, do you think your own standard of living now is much better, somewhat better, about the same, somewhat worse, or much worse than theirs was? ( $1=$ Much better, $2=$ Somewhat better, $3=$ About the same, $4=$ Somewhat worse, $5=$ Much worse)

(3) KIDSSOL (1994-2000): When your children are at the age you are now, do you think their standard of living will be much better, somewhat better, about the same, somewhat worse, or much worse than yours is now? ( $1=$ Much better, $2=$ Somewhat better, $3=$ About the same, $4=$ Somewhat worse, $5=$ Much worse)

\subsubsection{Current income.}

(1) REALINC (1978-1996): Family income on 1972-1996 surveys in constant dollars (base = 1986)

(2) REALRINC (1978-1996): Respondent's income on 1972-1996 surveys in constant dollars $($ base $=1986)$

(3) DEGREE (1978-2000): Respondent's degree (0 = Less than high school, $1=$ High school, 2 = Associate/junior college, 3 = Bachelor's, 4 = Graduate) 


\subsubsection{Confidence in government.}

(1) CONFED (1978-2000): I am going to name some institutions in this country. As far as the people running these institutions are concerned, would you say you have a great deal of confidence, only some confidence, or hardly any confidence at all in them? Executive branch of the federal government ( 1 = A great deal, $2=$ Only some, $3=$ Hardly any)

(2) CONLEGIS (1978-2000): I am going to name some institutions in this country. As far as the people running these institutions are concerned, would you say you have a great deal of confidence, only some confidence, or hardly any confidence at all in them? Congress $(1=$ A great deal, $2=$ Only some, $3=$ Hardly any)

8.2. Identity markers. Here identity variables are detailed where their description in the text is incomplete. Those variables are SEX, RACE, REGION, BORN, PARBORN, MADEG, RELIG16, and FUND16.

- $\operatorname{SEX}(1=$ Male, 2 = Female $)$

- RACE: What race would you consider yourself? (Recorded verbatim and coded) $(1=$ White, 2 = Black, $3=$ Other)

- REGION: In what state or foreign country were you living when you were 16 years old? (Coded by region) $(1=$ New England, $2=$ Middle Atlantic, $3=$ East North Central, $4=$ West North Central, $5=$ South Atlantic, $6=$ East South Central, $7=$ West South Central, $8=$ Mountain, $9=$ Pacific, $10=$ Foreign)

New England = Maine, Vermont, New Hampshire, Connecticut, Rhode Island, Massachusetts

Middle Atlantic $=$ New York, New Jersey, Pennsylvania

East North Central $=$ Wisconsin, Indiana, Ohio, Illinois, Michigan

West North Central = Minnesota, Iowa, Missouri, North Dakota, South Dakota, Missouri, Kansas

South Atlantic = Delaware, Maryland, West Virginia, Virginia, North Carolina, South Carolina, Georgia, Florida, District of Columbia

East South Central = Kentucky, Tennessee, Alabama, Mississippi

West South Central = Arkansas, Oklahoma, Louisiana, Texas

Mountain = Montana, Idaho, Wyoming, Nevada, Utah, Colorado, Arizona, New Mexico

Pacific $=$ Washington, Oregon, California, Alaska, Hawaii

- BORN: Were you born in this country? ( $1=$ Yes, $2=$ No; don't know responses were treated as missing values) 
- PARBORN: Were both of your parents born in this country? $(1=$ Both born in the US, 2 $=$ One born in the US, $3=$ Neither born in the US; don't know responses were treated as missing values)

- MADEG: Respondent's mother's education (Recoded by GSS from a set of questions regarding years of schooling and degrees attained) ( $0=$ Less than high school, $1=$ high school, 2 = Associate/junior college, 3 = Bachelor's, 4 = Graduate; don't know or NA responses treated as missing values)

- RELIG16: In what religion were you raised? $(1=$ Protestant, $2=$ Catholic, $3=$ Jewish, 4 $=$ None, $5=$ Other)

- FUND16: Fundamentalism/Liberalism of religion respondent raised in. (1 = Fundamentalist, $2=$ Moderate, $3=$ Liberal) 
Table 1

\begin{tabular}{|c|c|c|c|}
\hline \multicolumn{4}{|c|}{ Summary of Identity Variables } \\
\hline Identity Marker & Years & Mean & Standard Deviation \\
\hline SEX & $1978-2000$ & 1.56 & 0.50 \\
\hline RACE & $1978-2000$ & 1.16 & 0.44 \\
\hline REG16 & $1978-2000$ & 4.37 & 2.46 \\
\hline BORN & $1978-2000$ & 1.06 & 0.24 \\
\hline PARBORN & $1978-2000$ & 1.24 & 0.60 \\
\hline MADEG & $1978-2000$ & 0.81 & 0.94 \\
\hline RELIG16 & $1978-2000$ & 1.47 & 0.73 \\
\hline FUND16 & $1978-2000$ & 1.90 & 0.74 \\
\hline AGE & $1978-2000$ & 44.78 & 16.98 \\
\hline
\end{tabular}

Please use this table in conjunction with the Data appendix of paper,

that includes a complete description of each question. 
Table 2

\begin{tabular}{|r|r|r|r|}
\hline \multicolumn{1}{|l|}{ Summary of Dependent Variables } \\
\hline Dependent Variable & Years & Mean & Standard Deviation \\
\hline EQWLTH & $1978-2000$ & 3.76 & 1.95 \\
\hline NATFARE & $1978-2000$ & 2.32 & 0.77 \\
\hline INCGAP & $1987,1996,2000$ & 2.34 & 1.13 \\
\hline WHYPOOR4 & 1990 & 1.62 & 0.63 \\
\hline GETAHEAD & $1980-2000$ & 1.45 & 0.70 \\
\hline OPHRDWRK & 1987 & 1.75 & 0.69 \\
\hline LFEHRDWK & 1993 & 1.49 & 0.64 \\
\hline PADEG_ABS_DIF & $1978-2000$ & 0.94 & 1.03 \\
\hline PARSOL & $1994-2000$ & 2.21 & 1.11 \\
\hline KIDSSOL & $1994-2000$ & 2.79 & 1.55 \\
\hline REALINC & $1978-1996$ & 31075.67 & 26563.77 \\
\hline REALRINC & $1978-1996$ & 20299.39 & 18686.24 \\
\hline DEGREE & $1978-2000$ & 1.43 & 1.17 \\
\hline CONFED & $1978-2000$ & 2.16 & 0.67 \\
\hline CONLEGIS & $1978-2000$ & 2.17 & 0.62 \\
\hline \multicolumn{4}{|l}{} \\
\hline $\begin{array}{l}\text { Please use this table in conjunction with the Data appendix of paper, } \\
\text { that includes a complete description of each question. }\end{array}$ \\
\hline
\end{tabular}


Table 3A

\section{Tree regressions}

Preference for public redistribution

\section{Dependent variables}

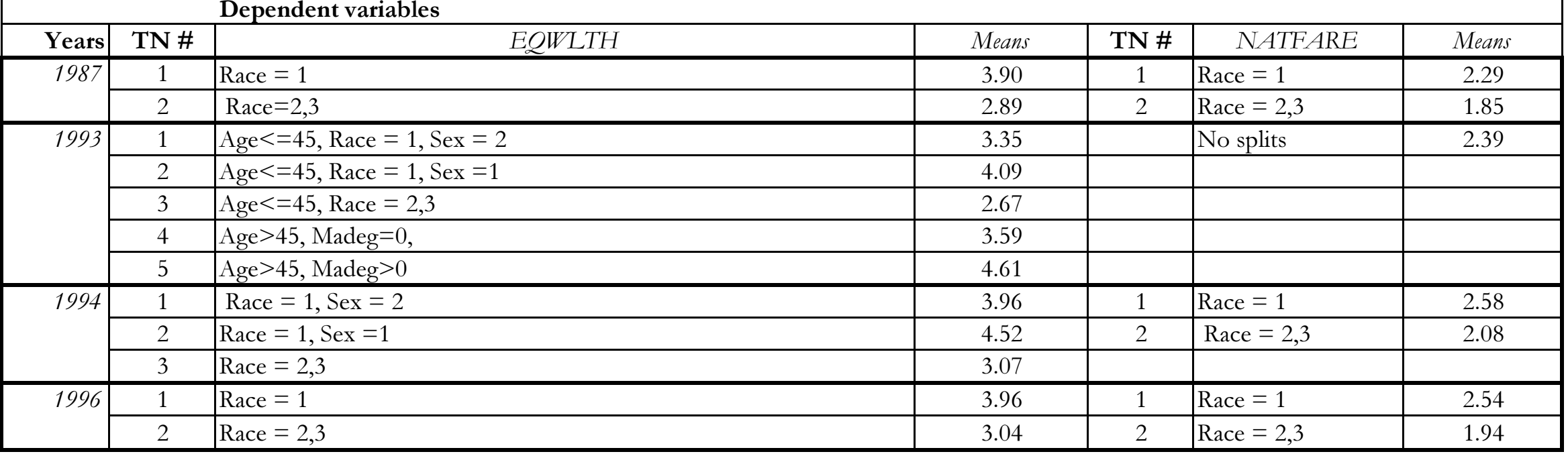


Table 3B

Tree regressions

Preference for public redistribution

\begin{tabular}{|c|c|c|c|c|c|c|}
\hline \multicolumn{7}{|c|}{ Dependent variables } \\
\hline Years & TN\# & EQWLTH & Means & TN \# & NATFARE & Means \\
\hline \multirow[t]{6}{*}{2000} & 1 & Sex $=2$ & 3.62 & & No splits & 2.20 \\
\hline & 2 & Sex $=1$, Race $=1$, Madeg $<=0, \operatorname{Reg} 16=3,4,5,7,9$ & 4.33 & & & \\
\hline & 3 & Sex $=1$, Race $=1$, Madeg $<=0, \operatorname{Reg} 16=0,1,2,6$ & 3.05 & & & \\
\hline & 4 & Sex $=1$, Race $=1$, Madeg $>0$, Age $<=34$ & 3.97 & & & \\
\hline & 5 & Sex $=1$, Race $=1$, Madeg $>0$, Age $>34$ & 4.63 & & & \\
\hline & 6 & Race $=2,3$ & 3.10 & & & \\
\hline \multirow{3}{*}{$1994-2000$} & 1 & Race $=1$, Sex $=2$ & 3.87 & 1 & Year $=1994,1996$, Race $=1$ & 2.56 \\
\hline & 2 & Race $=1$, Sex $=1$ & 4.32 & 2 & Year $=1994,1996$, Race $=2,3$ & 2.01 \\
\hline & 3 & Race $=2,3$ & 3.17 & 3 & Year $=1998,2000$ & 2.25 \\
\hline \multirow[t]{5}{*}{$1978-2000$} & & Large (13) & & 1 & Year $=1978,1980,1993,1994,1996$, Race $=1$, Age $<=28$ & 2.40 \\
\hline & & & & 2 & Year $=1978,1980,1993,1994,1996$, Race $=1$, Age $>28$ & 2.56 \\
\hline & & & & 3 & Year $=1978,1980,1993,1994,1996$, Race $=2,3$ & 2.00 \\
\hline & & & & 4 & Year $=1983,1984,1986,1987,1988,1989,1990,1991,1998,2000$, Race $=1$ & 2.27 \\
\hline & & & & 5 & Year $=1983,1984,1986,1987,1988,1989,1990,1991,1998,2000$, Race $=2,3$ & 1.93 \\
\hline
\end{tabular}


Table 4

\begin{tabular}{|c|c|c|c|c|}
\hline \multicolumn{5}{|c|}{$\begin{array}{l}\text { Tree regressions } \\
\text { Tolerance for inequality }\end{array}$} \\
\hline \multicolumn{5}{|c|}{ Dependent variables } \\
\hline Years & INCGAP & Means & WHYPOOR4 & Means \\
\hline 1987 & No splits & 2.45 & - & - \\
\hline 1990 & - & - & No splits & 1.62 \\
\hline 1996 & No splits & - & - & - \\
\hline 2000 & No splits & 2.30 & - & - \\
\hline $1994-2000$ & - & 2.23 & - & - \\
\hline $1978-2000$ & No splits* & 2.34 & - & - \\
\hline
\end{tabular}




\section{Table 5}

Tree regressions

Confidence in government

\begin{tabular}{|c|c|c|c|c|c|c|}
\hline \multicolumn{7}{|c|}{ Dependent variables } \\
\hline Years & TN \# & CONFED & Means & TN \# & CONLEGIS & Means \\
\hline 1987 & & No splits & 2.11 & & No splits & 2.02 \\
\hline 1993 & & No splits & 2.21 & & No splits & 2.35 \\
\hline 1994 & & No splits & 2.26 & & No splits & 2.34 \\
\hline 1996 & & No splits & 2.34 & & No splits & 2.38 \\
\hline \multirow[t]{2}{*}{2000} & & No splits & 2.22 & 1 & Born $=2$ & 1.85 \\
\hline & & & & 2 & Born $=1$ & 2.20 \\
\hline \multirow[t]{3}{*}{$1994-2000$} & 1 & Relig16 $=1,2,4$, Parborn $=1,2$ & 2.29 & 1 & Year $=1994,1996$ & 2.36 \\
\hline & 2 & Relig16 $=1,2,4$, Parborn $=3$ & 1.98 & 2 & Year $=1998,2000$ & 2.19 \\
\hline & 3 & Relig16 = 3 & 1.98 & & & \\
\hline \multirow[t]{5}{*}{$1978-2000$} & & Year $=1980,1993,1994,1996,1998,2000$, Parborn $=1$ & 2.28 & & Year $=1980,1993,1994,1996$ & 2.34 \\
\hline & & Year $=1980,1993,1994,1996,1998,2000$, Parborn $=2,3$ & 2.12 & & Year $=1978,1983-91,1998,2000$ & 2.10 \\
\hline & & Year $=1978,1983,1984,1986,1987,1988,1989,1990,1991$, Race $=2$ & 2.23 & & & \\
\hline & & Year $=1978,1983,1984,1987,1988$, Race $=1,3$ & 2.10 & & & \\
\hline & & Year $=1986,1989,1990,1991$, Race $=1,3$ & 1.98 & & & \\
\hline
\end{tabular}


Table 6

\section{Tree regressions}

Mobility beliefs

Dependent variables

\begin{tabular}{|c|c|c|c|c|c|c|}
\hline Years & GETAHEAD & Means & OPHRDWK & Means & LFEHRDWK & Means \\
\hline 1987 & No splits & 1.51 & No splits & 1.74738 & - & - \\
\hline 1993 & No splits & 1.46 & - & - & No splits & 1.49 \\
\hline 1994 & No splits & 1.40 & - & - & - & - \\
\hline 1996 & No splits & 1.41 & - & - & - & - \\
\hline 2000 & No splits & 1.46 & - & - & - & - \\
\hline 1994-2000 & No splits & 1.43 & - & - & - & - \\
\hline $1978-2000$ & No splits* & 1.45 & - & - & - & - \\
\hline
\end{tabular}


Table 7

Tree regressions

Mobility

\begin{tabular}{|c|c|c|c|c|c|c|c|c|c|}
\hline \multirow[b]{2}{*}{ Years } & \multicolumn{3}{|c|}{ Dependent variables } & \multirow[b]{2}{*}{ TN \# } & \multirow[b]{2}{*}{ PARSOL } & \multirow[b]{2}{*}{ Means } & \multirow[b]{2}{*}{ TN \# } & \multirow[b]{2}{*}{ KIDDSOL } & \multirow[b]{2}{*}{ Means } \\
\hline & TN \# & PADEG_ABS_DIFF & Means & & & & & & \\
\hline \multirow[t]{3}{*}{1987} & 1 & Age $<=50$ & 1.00 & & - & - & & - & - \\
\hline & 2 & Age $>50$, Madeg $<=0$ & 0.57 & & & & & & \\
\hline & 3 & Age $>50$, Madeg $>0$ & 1.06 & & & & & & \\
\hline 1993 & & No splits & 1.00 & & - & - & & - & - \\
\hline 1994 & & No splits & 1.00 & & No splits & 2.26 & & No splits & 2.61 \\
\hline \multirow[t]{2}{*}{1996} & & No splits & 1.02 & 1 & Madeg $<=0$ & 1.93 & & No splits & 2.57 \\
\hline & & & & 2 & Madeg $>0$ & 2.42 & & & \\
\hline 2000 & & No splits & 0.99 & & No splits & 2.15 & & No splits & 2.12 \\
\hline \multirow[t]{3}{*}{$1994-2000$} & & Madeg $<=2$, Age $<=39$ & 0.84 & 1 & Age $<=55$ & 2.32 & 1 & Year $=1994,1996$ & 2.59 \\
\hline & & Madeg $<=2$, Age $>39$ & 1.08 & 2 & Age $>55$ & 1.90 & 2 & Year $=1998,2000$, Race $=1$ & 2.29 \\
\hline & & Madeg $>2$ & 1.16 & & & & 3 & Year $=1998,2000$, Race $=2,3$ & 1.90 \\
\hline $1978-2000$ & & Large (8) & - & & - & - & & - & - \\
\hline
\end{tabular}


Table 8

Tree regression

Current income

Dependent variables

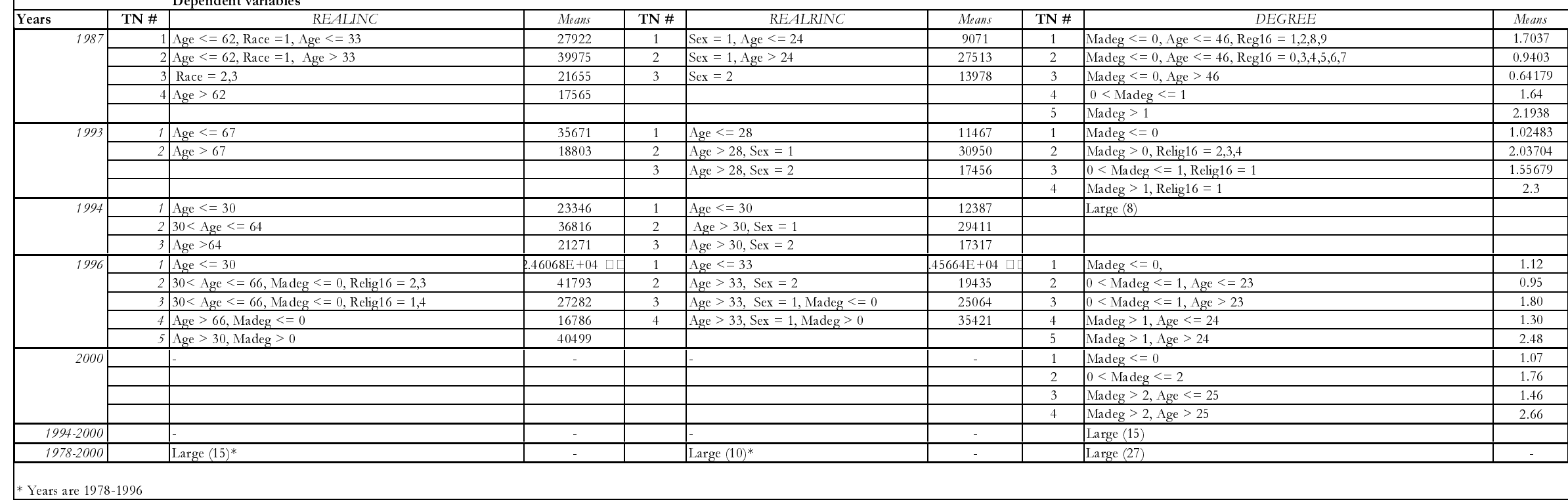




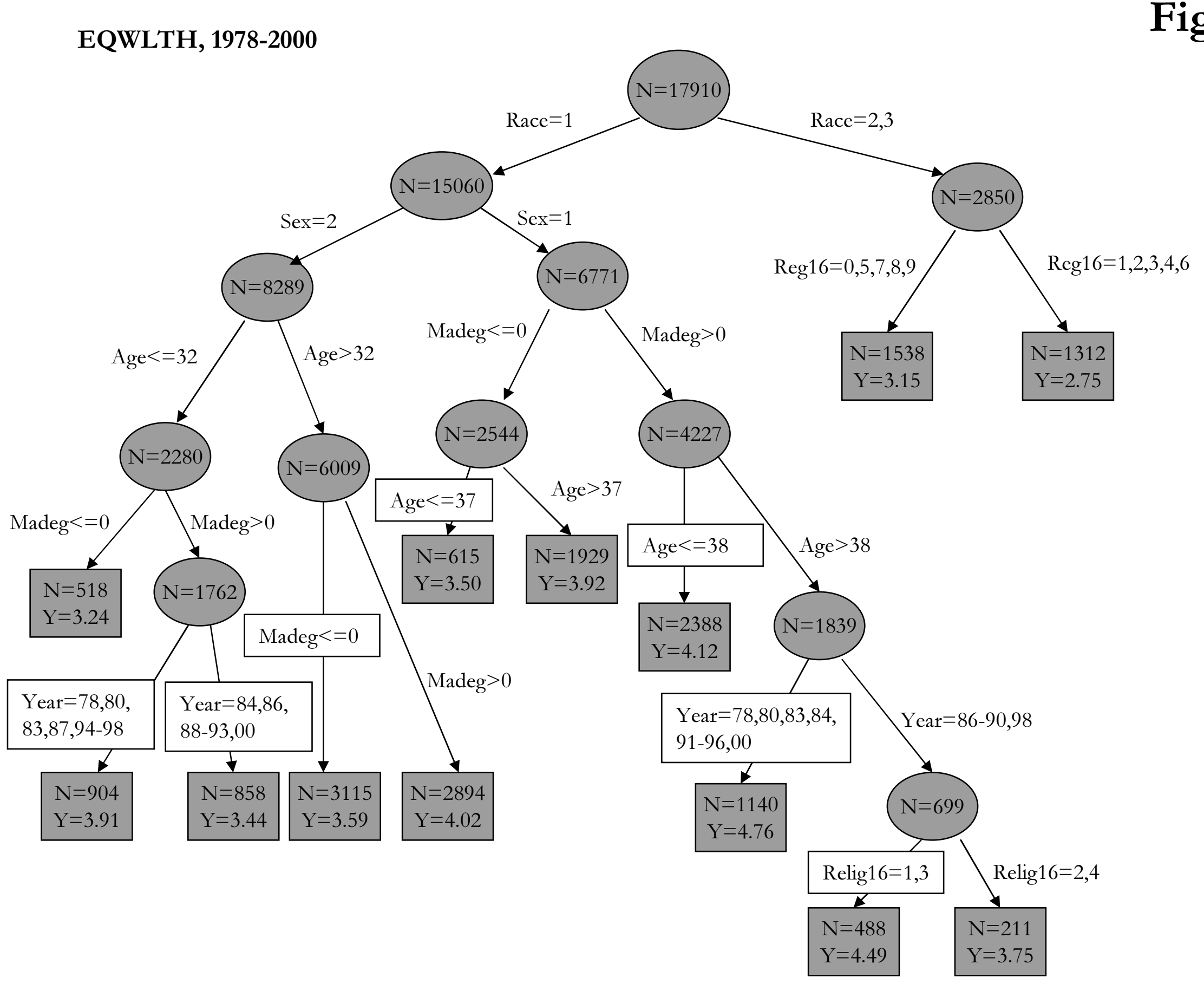


PADEG_ABS_DIF, 1978-2000

Figure 2

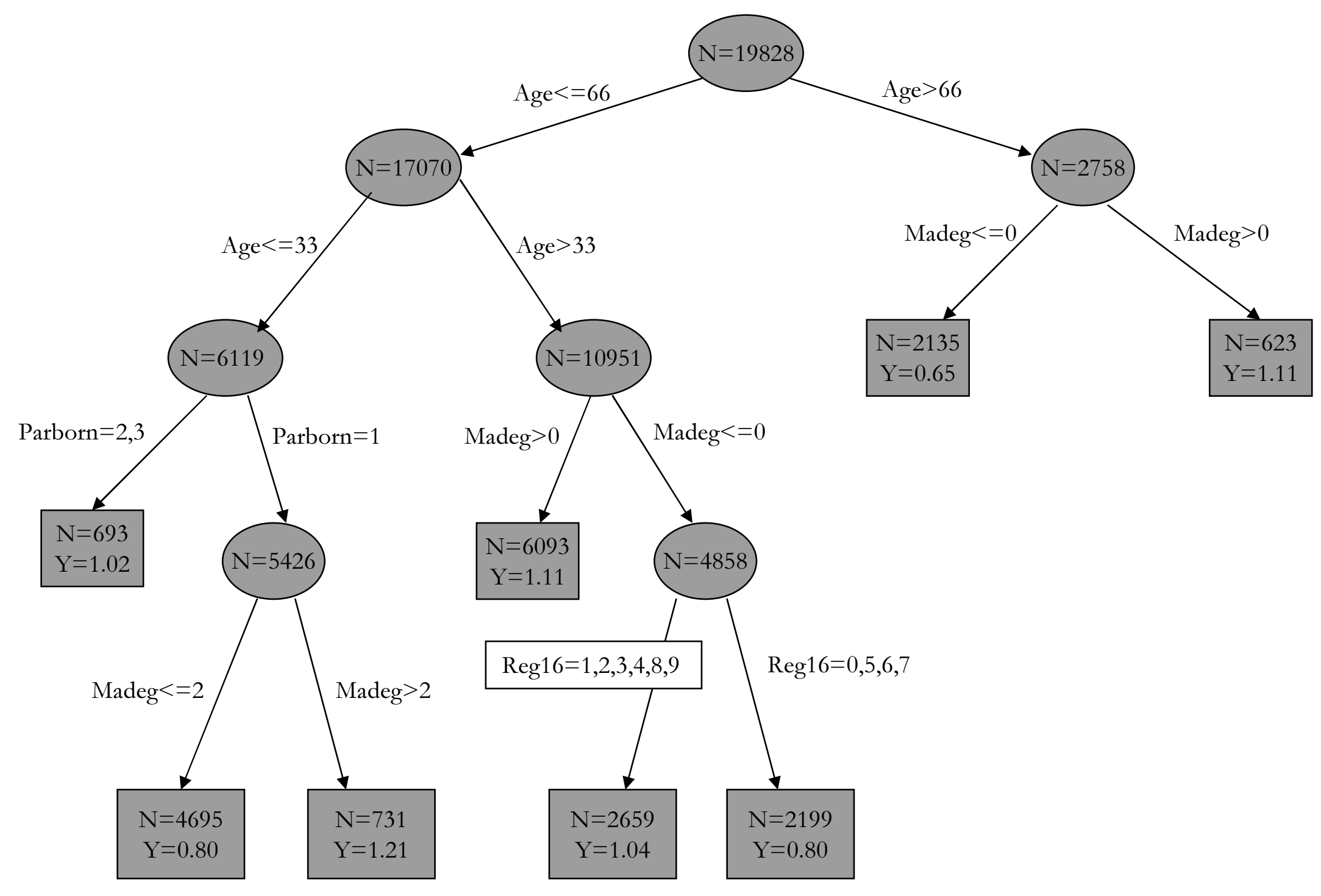




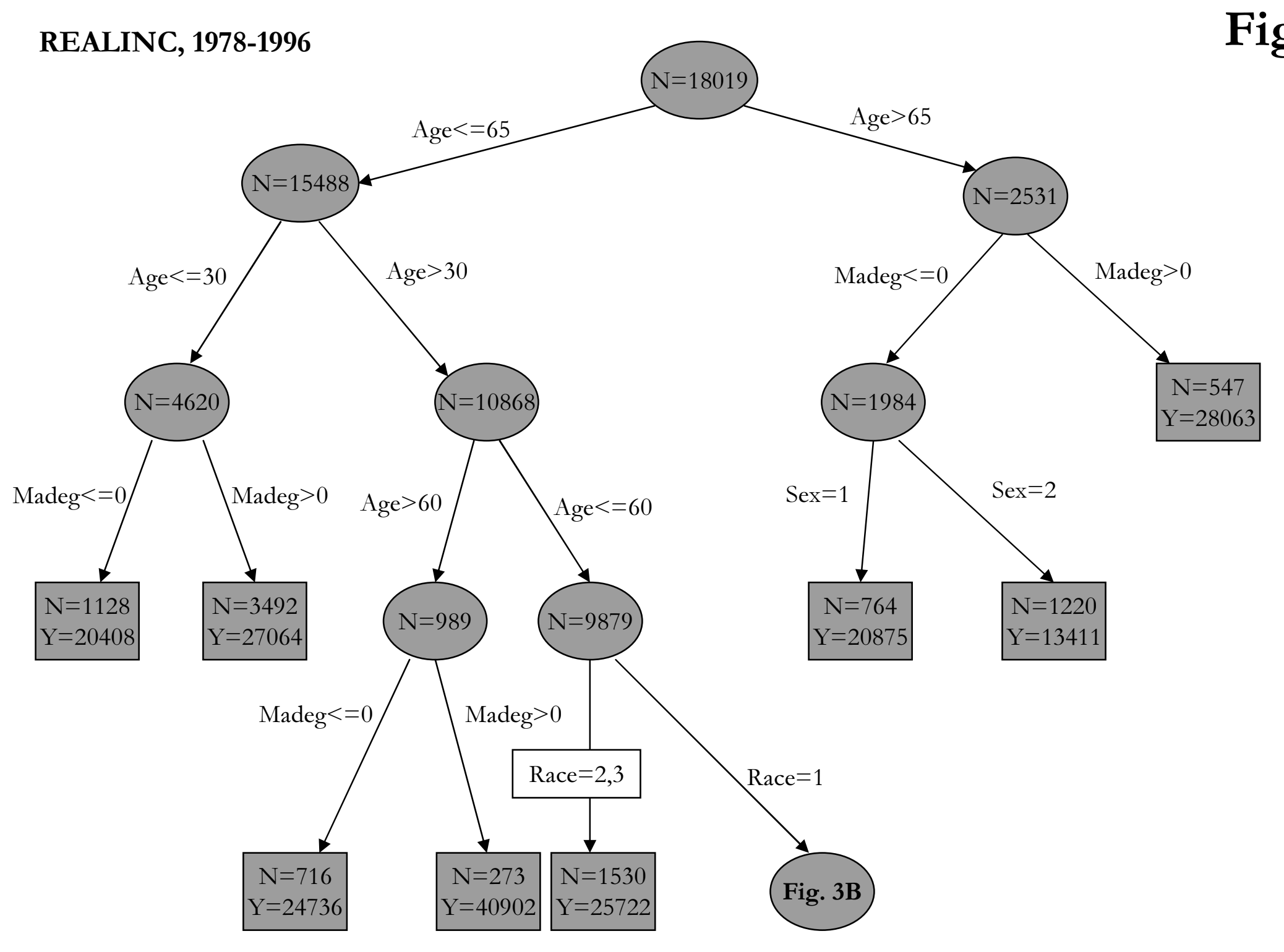




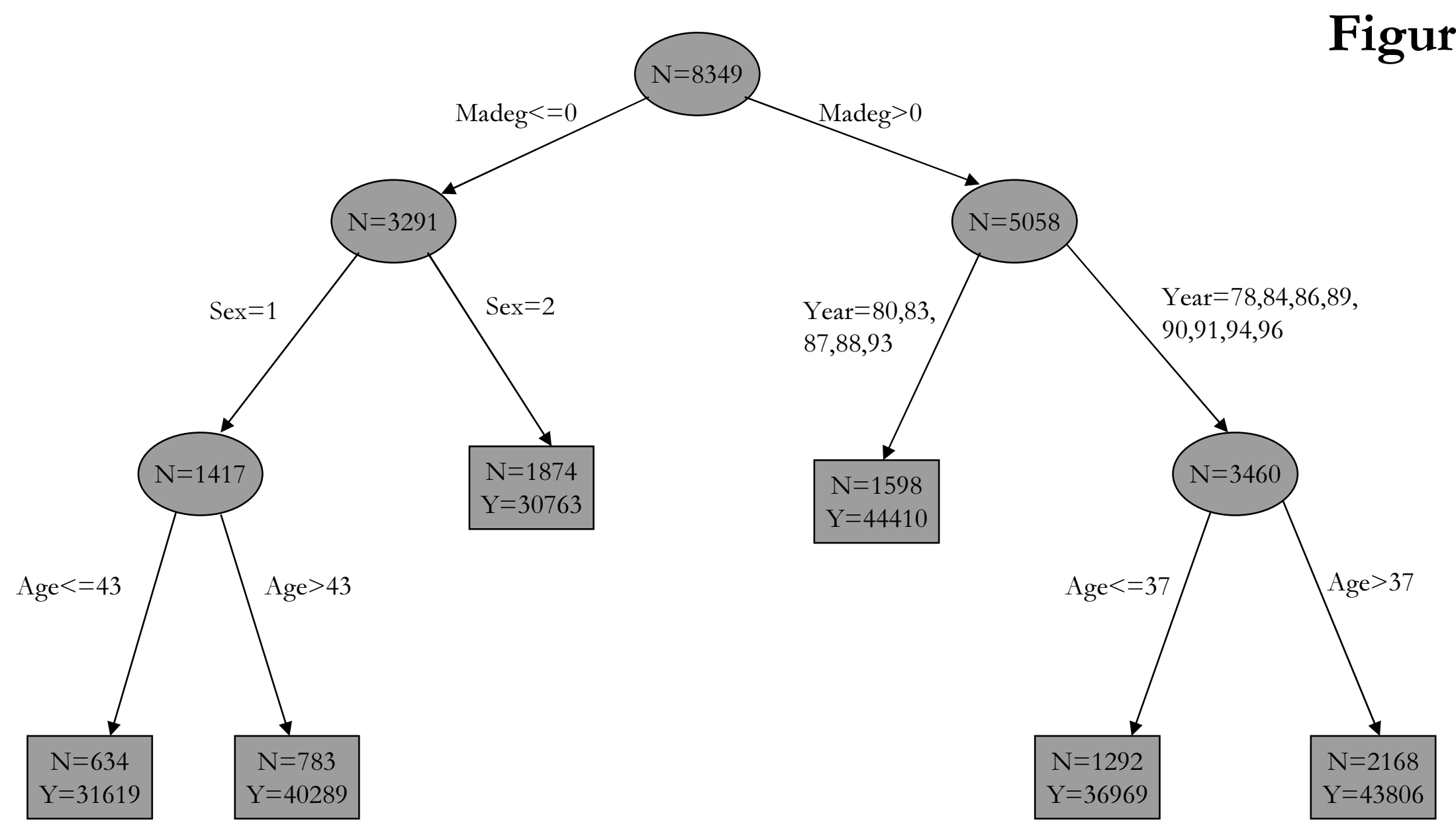




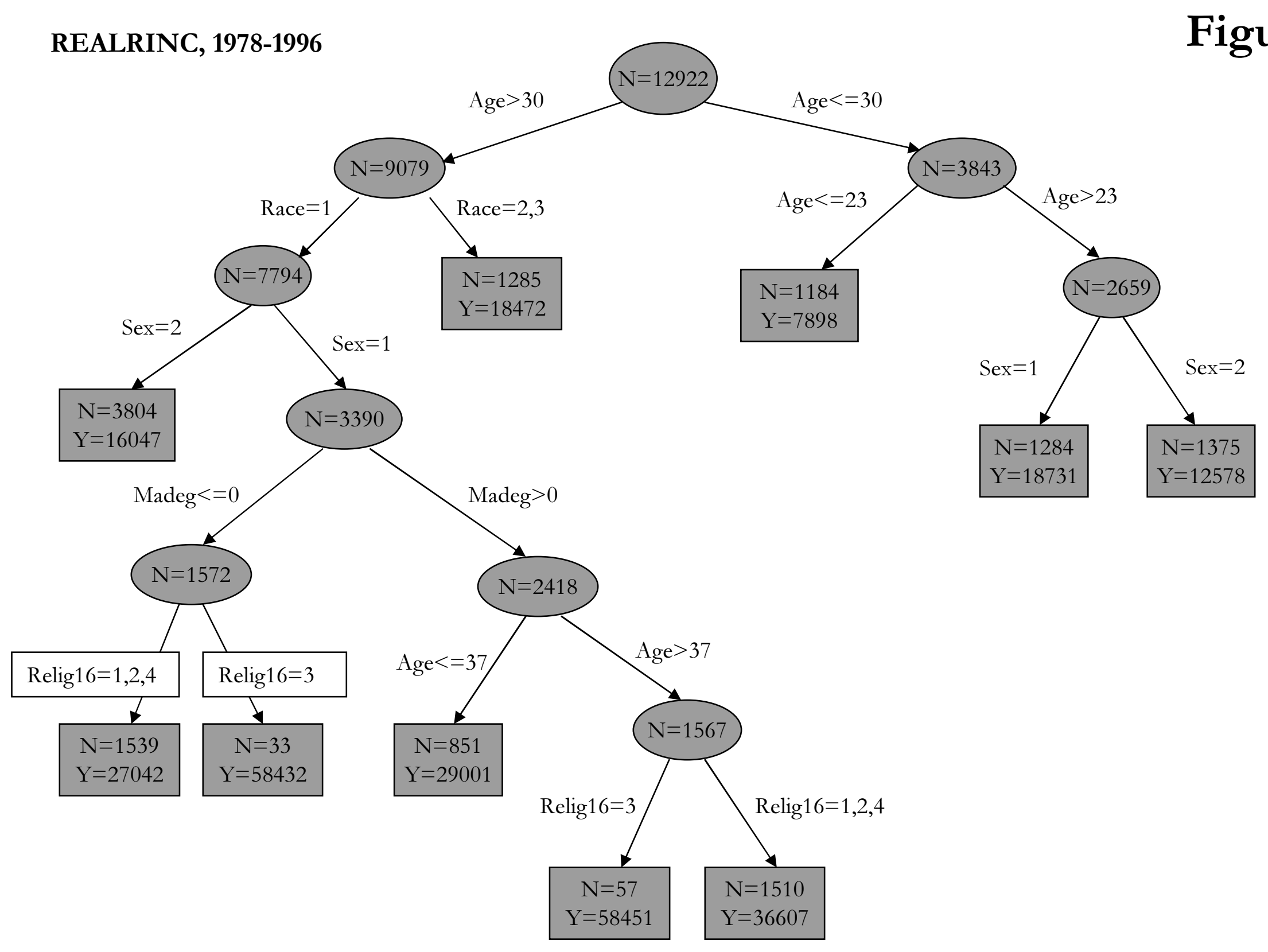




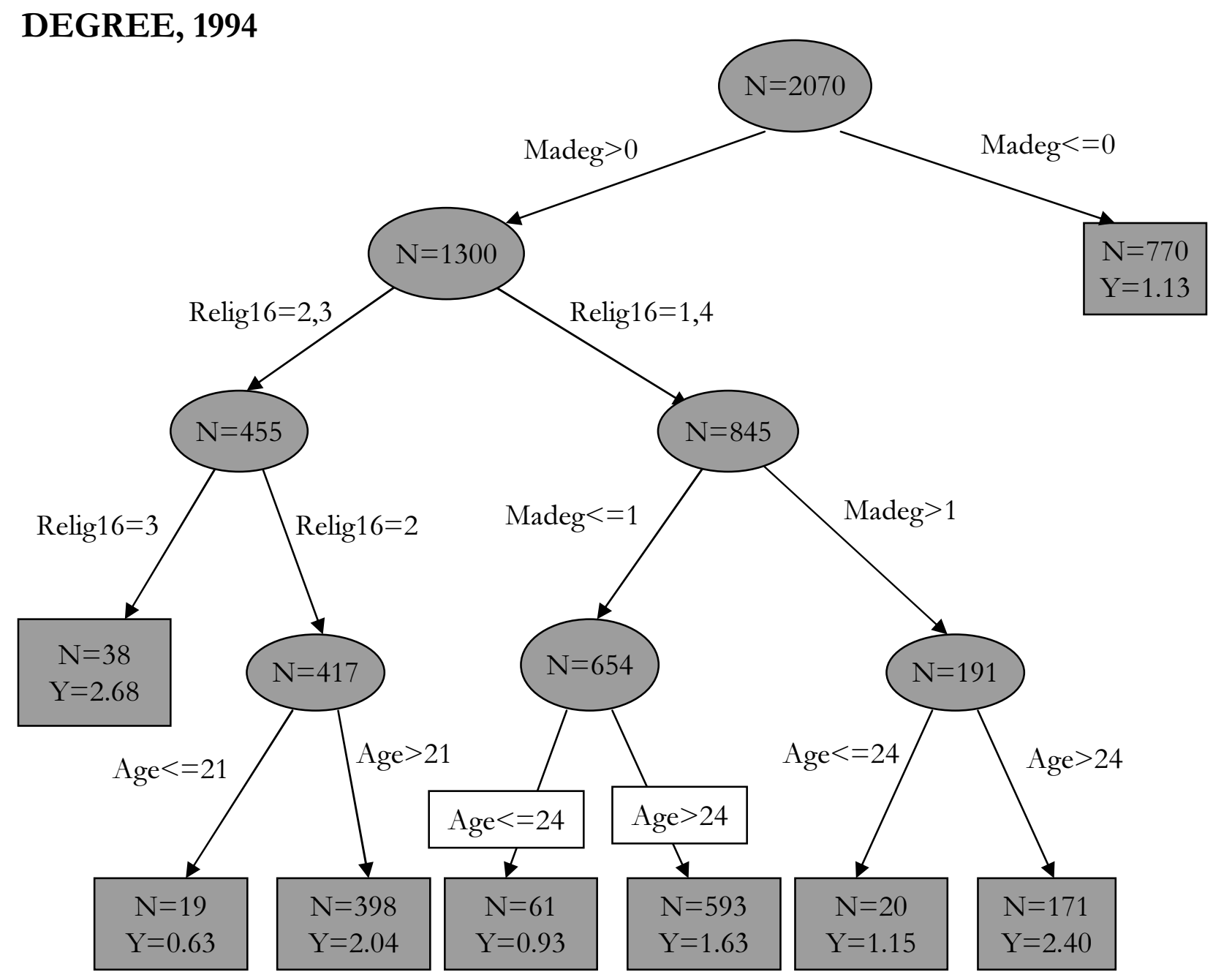

Figure 5 


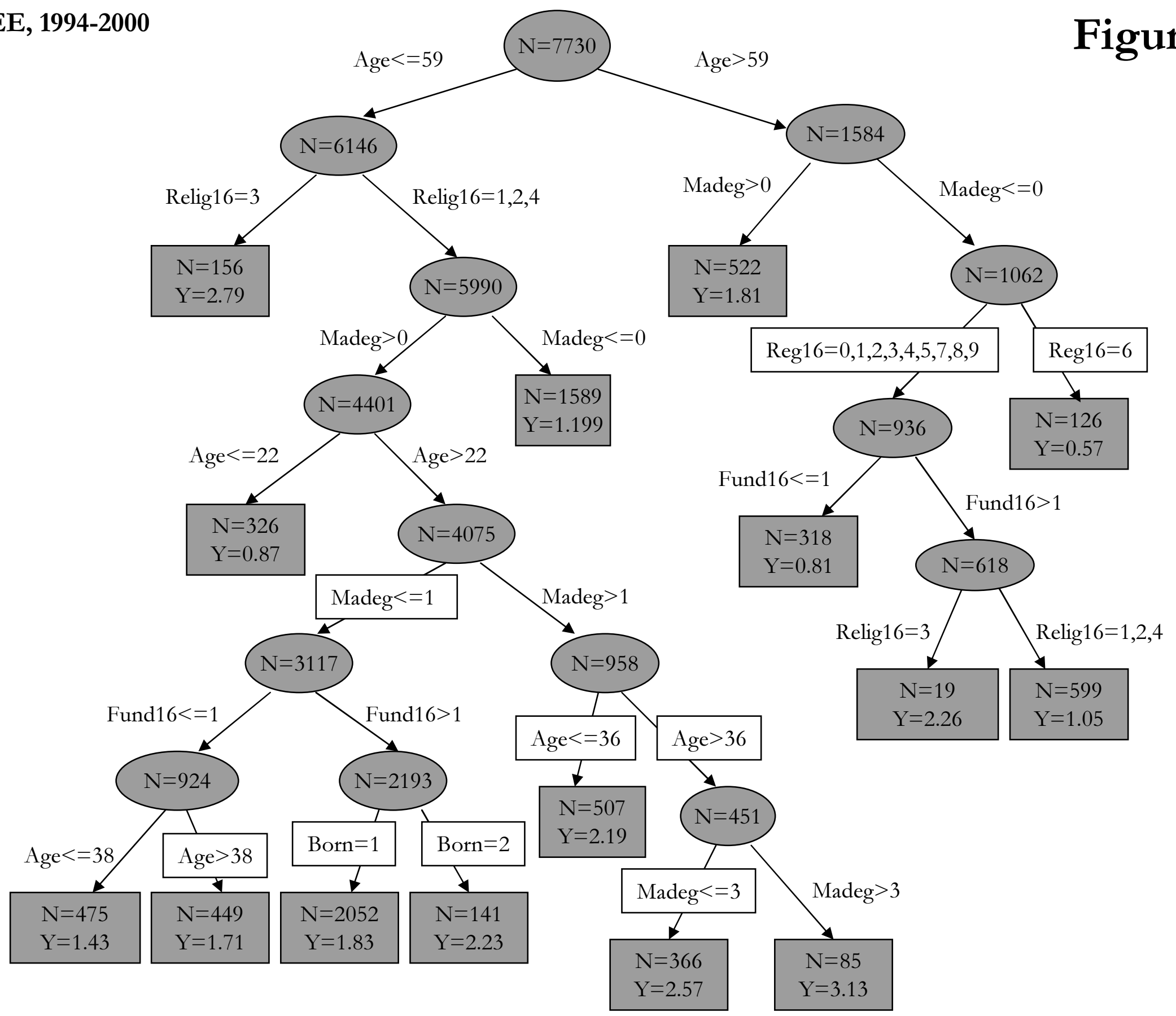




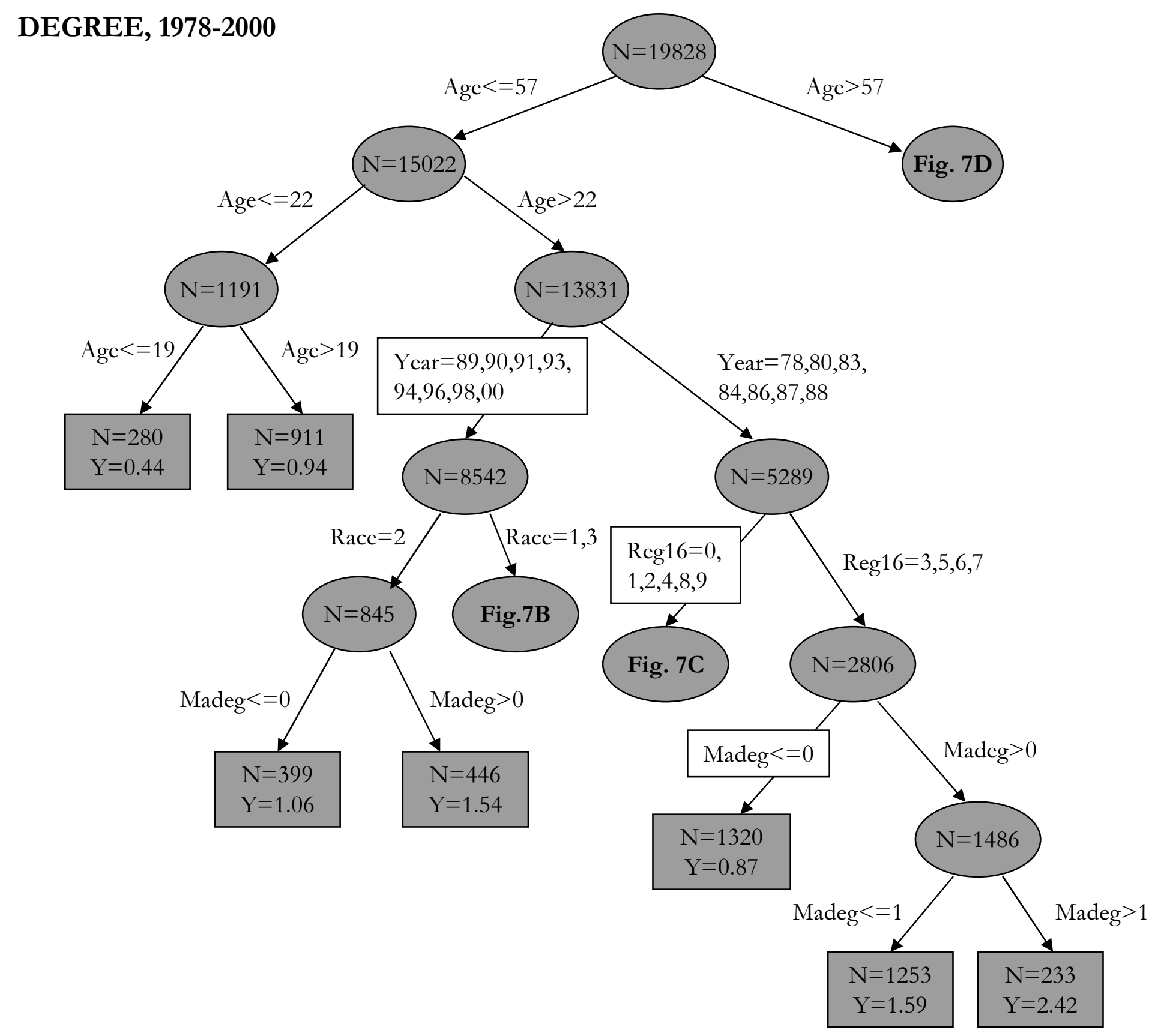

Figure 7A 


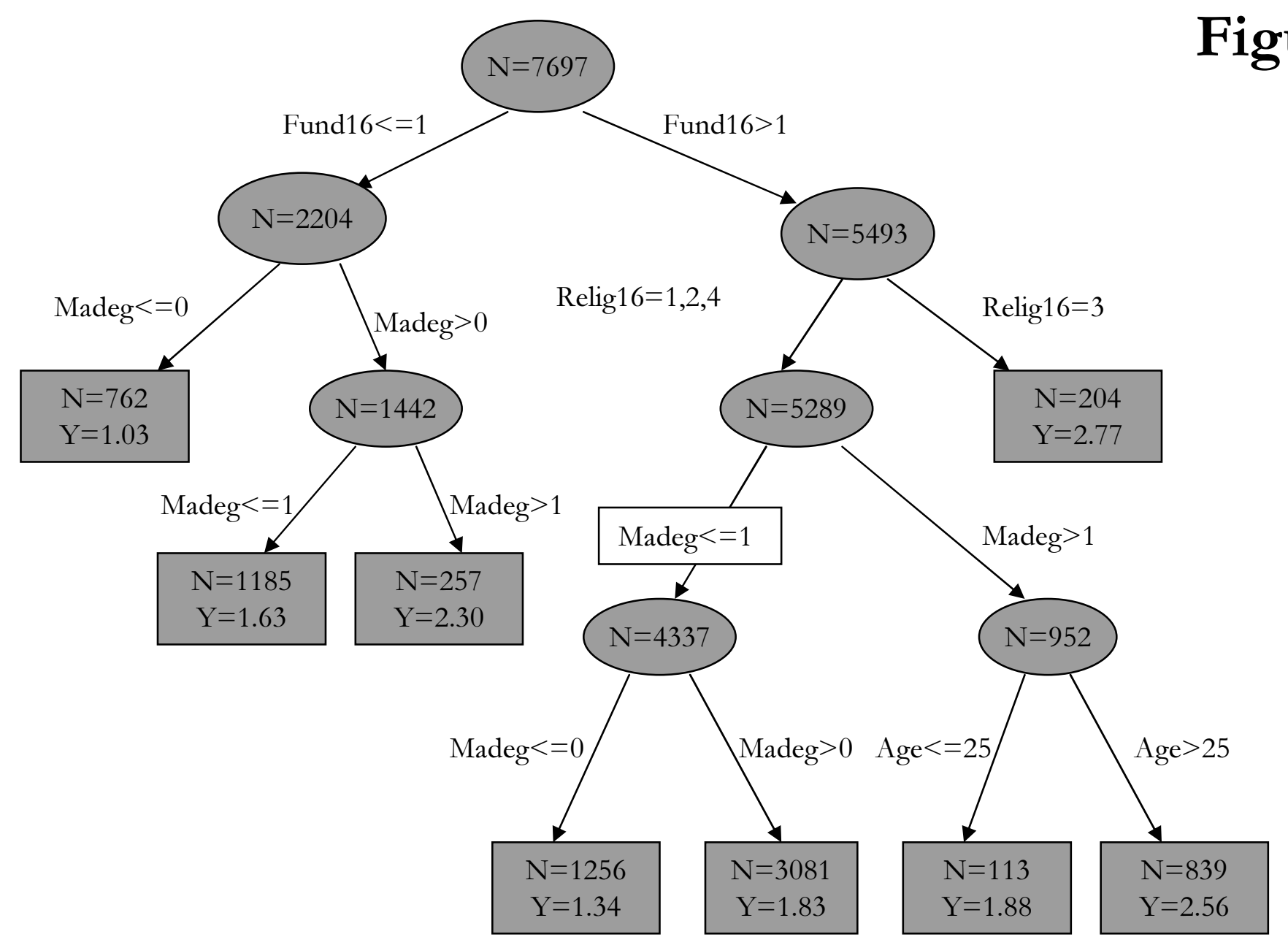




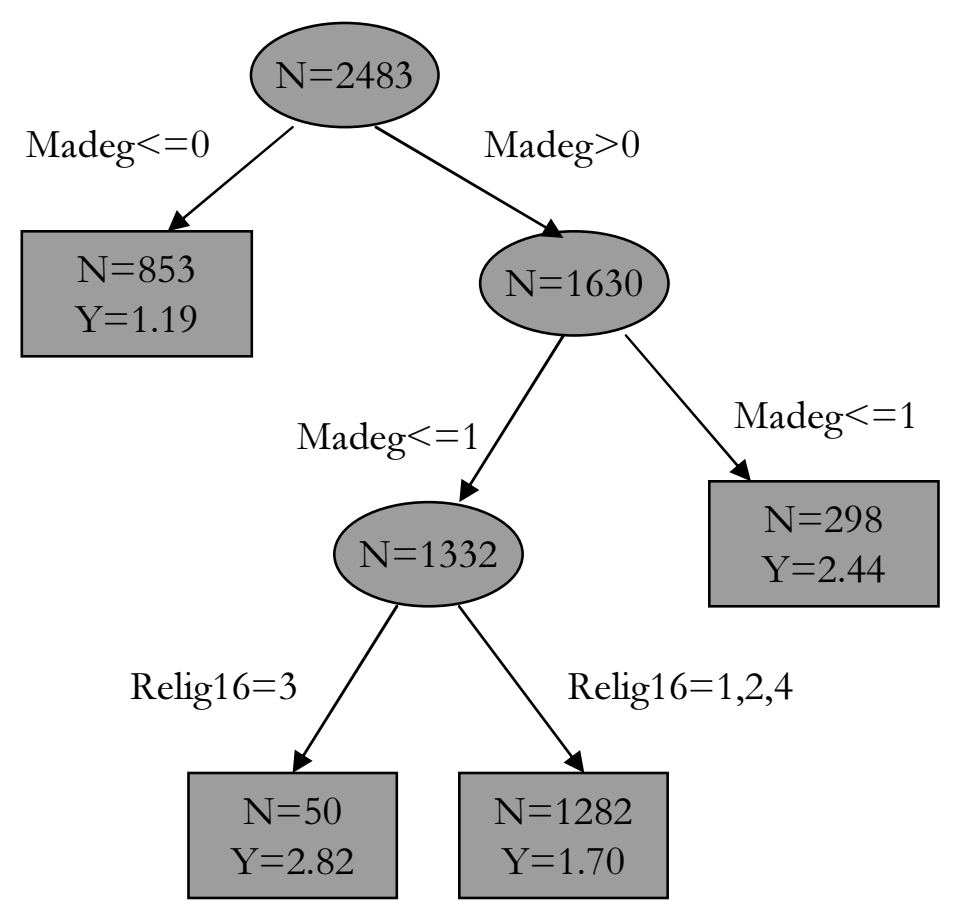

Figure 7C 


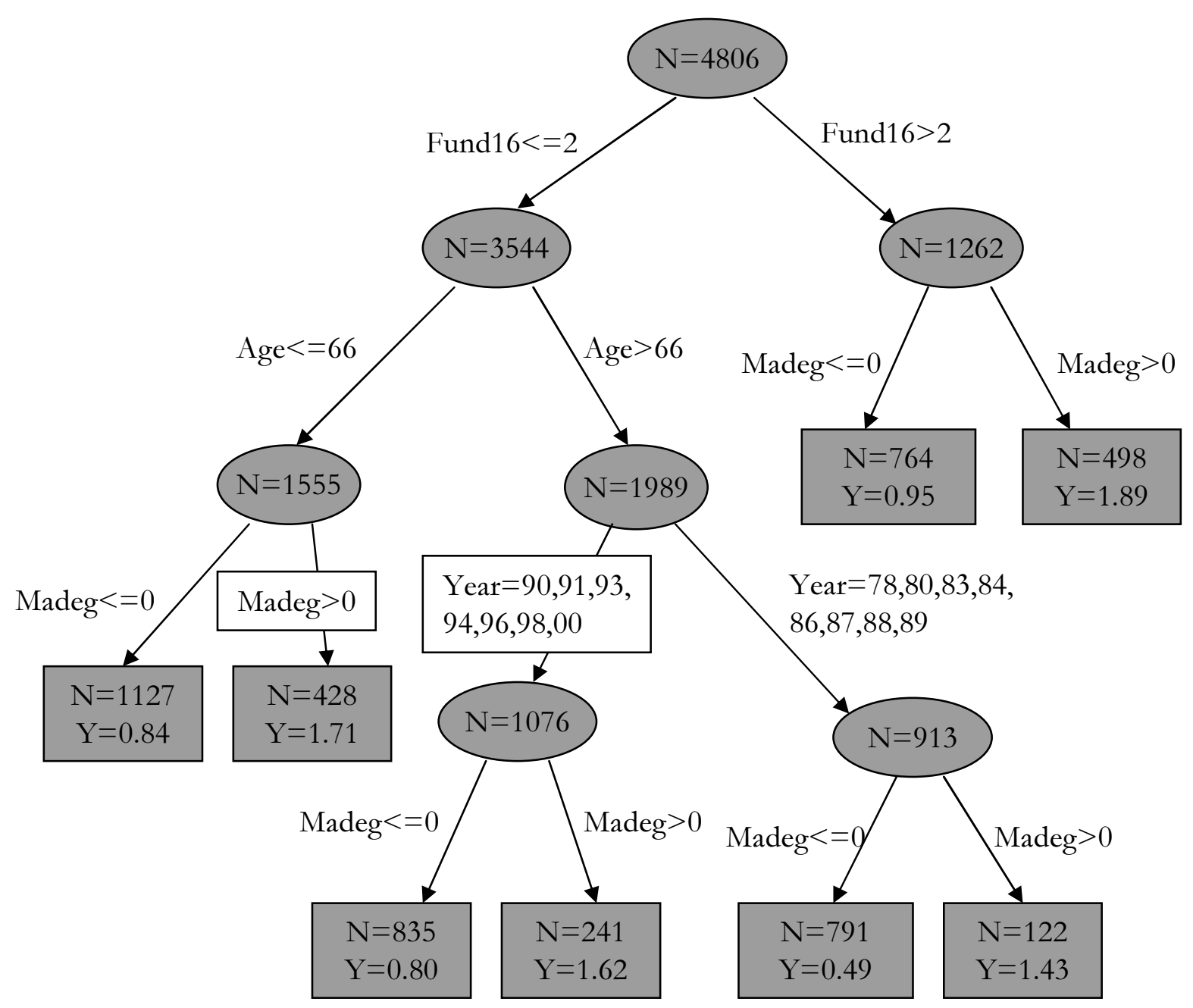

Figure 7D 